\title{
One year after twin earthquakes in Northwest Iran
}

\author{
Arash Babaei-Ghazani • Bina Eftekhar Sadat
}

Received: 21 January 2014/ Accepted: 21 January 2014/Published online: 13 February 2014

(C) The Japanese Society for Hygiene 2014

\begin{abstract}
Every year in most earthquakes more than thousands of lives are lost, mainly in middle- and lowincome countries. Disability and rehabilitation in third world countries could cause disastrous negative effect in living expense of families. So many preventable disabilities are result of these earthquakes and we hope reminding it will make a difference.
\end{abstract}

Keywords Earthquake $\cdot$ Disability $\cdot$ Rehabilitation · Psychology $\cdot$ Live

On 11 August 2012, twin earthquakes measured 6.3 and 6.4 on the Richter scale hit three towns (Ahar, Varzaqan, and Heris) and their neighboring villages in East Azerbaijan Province, Iran resulting in tragic loss of three hundred lives and leaving thousands of injured [1].

There were more than 120 damaged villages which 20 of them were nearly flattened. After immediate rescue efforts, emergency sheltering and basic food and water supplying with government and non-government organizations, focus became at reconstruction which included two severely damaged hospitals, electricity and clean water pipe lines, more than 20,000 destroyed houses in more than 120 villages and 3 towns. One year after that tragic natural disaster about $90 \%$ reconstruction progressed.

In the prospective of earthquake victims, after acute and sub-acute treatments, now victims' medical care needs are

\footnotetext{
A. Babaei-Ghazani

Department of Physical Medicine and Rehabilitation,

Iran University of Medical Sciences, Tehran, Iran

B. Eftekhar Sadat $(\bowtie)$

Physical Medicine and Rehabilitation Research Center,

Tabriz University of Medical Sciences, Tabriz, Iran

e-mail: binasadat@yahoo.com
}

changed mainly toward rehabilitation medicine and psychological interventions for those mostly affected. Based on reports of 26 patients with neurological complications from spinal cord or traumatic brain injuries [2], long-term rehabilitation measures seem to be a great issue which sometimes may need assistive devices and rehabilitation medicine equipments in referral centers away from that region.

Overall 1 year after twin earthquakes, rebuilding the damaged areas is progressing in a great deal but there is still human suffering and need for medical care and support especially in rehabilitation and psychology fields which reminds us long-term commitment is necessary for all agencies involved in secondary and tertiary prevention for earthquake victims. Recent 7.8 magnitude earthquake in Pakistan-neighboring country-shows that it is reasonable to highlight the fact that earthquake safety guidelines for buildings should be taken seriously especially in health centers and kept in mind the multi-disciplinary rehabilitation support and other clinical and mental medical cares for earthquake victims.

Conflict of interest No funding or grants or equipment provided for the project from any source and there are no financial benefits to the authors.

\section{References}

1. Golzari SE, Ghabili K. Twin earthquakes in northwest Iran. Lancet. 2012;380(9851): 1384.

2. Ghabili K, Golzari SE, Salehpour F, Imani T, Bazzazi AM, Ghaffari A, Khanli HM, Tizro P, Taghizade S, Shakouri SK. Spinal injuries in the 2012 twin earthquakes, northwest Iran. PLoS Curr. 2013;27:5. 